\title{
Synthesis and performance of AM/SSS/THDAB as clay hydration dispersion inhibitor
}

\author{
Wei-Chao Du ${ }^{1,2 *}$ (D), Xiang-Yun Wang ${ }^{1}$, Man Liü ${ }^{3}$, Tai-Fei Bi ${ }^{4}$, Shun-Xi Song' ${ }^{2}$, Jie Zhang ${ }^{1}$ and Gang Chen ${ }^{1}$ \\ ${ }^{1}$ College of Chemistry and Chemical Engineering, Xi'an Shiyou University, Xi'an, People's Republic of China \\ ${ }^{2}$ Key Laboratory of Auxiliary Chemistry and Technology for Chemical Industry, Ministry of Education, \\ Shaanxi University of Science and Technology, Xi'an, People's Republic of China \\ ${ }^{3}$ Oil Production No.11, Changqing Oilfield Company, Qingyang, People's Republic of China \\ ${ }^{4}$ Oil Production No.1, Changqing Oilfield Company, Yan'an, People's Republic of China \\ *duweichao@xsyu.edu.cn
}

\begin{abstract}
In this paper, a novel zwitterionic copolymer AM/SSS/THDAB clay hydration dispersion inhibitor was synthesized by copolymerization of tris hydroxyethyl diallyl ammonium bromide (THDAB), sodium p-styrene sulfonate (SSS) and acrylamide (AM) initiated in an aqueous solution. The copolymer was characterized by FT-IR, GPC, TGA-DSC and SEM. Results demonstrated that molecular weight of AM/SSS/THDAB was $43674 \mathrm{~g} / \mathrm{mol}$ and its temperature resistance ability was up to $225{ }^{\circ} \mathrm{C}$. Evaluation experiments showed that AM/SSS/THDAB has an excellent clay hydration inhibitive performance. Methods including particle size analysis and SEM were utilized to study its dispersion inhibition mechanism by using sodium montmorillonite (Na-MMT). Results indicated that the micro-structure of Na-MMT has been successfully changed by AM/SSS/THDAB. In a word, the superior inhibition property makes the novel clay hydration dispersion inhibitor promised in water-based drilling fluids.
\end{abstract}

Keywords: clay hydration inhibitor, low molecular weight, shale gas, water-based drilling fluids.

How to cite: Du, W.-C., Wang, X.-Y., Liu, M., Bi, T.-F., Song, S.-X., Zhang, J., \& Chen, G. (2019). Synthesis and performance of AM/SSS/THDAB as clay hydration dispersion inhibitor. Polímeros: Ciência e Tecnologia, 29(4), e2019053. https://doi.org/10.1590/0104-1428.06519

\section{Introduction}

Drilling fluids are multicomponent systems used to aid the removal of cuttings from a borehole, and subject to a number of requirements to ensure a safe drilling operation ${ }^{[1]}$. The exploitation of unconventional reservoir such as shale gas has raised the attention of the world while the excessive depletion of conventional reservoir. However, the wellbore instability will be the major problem associated with the drilling operation of shale gas formations ${ }^{[2]}$. Generally, oil based muds (OBMs) is always the primary choice due to its superior clay hydration inhibition ability so as to avoid wellbore instability problem. Unfortunately, the environmental restrictions and high costs have largely limited the wide application of $\mathrm{OBMs}^{[3]}$. At the same time, water-based drilling fluids (WBDFs) is often employed in drilling of unconventional reservoir due to its simple formulation and low cost. Because the wellbore instability is due to hydration dispersion of clay minerals in shale. The development of clay hydration dispersion inhibitor and high performance WBDFs are the timely pursuit of drilling engineering ${ }^{[4-7]}$.

Various large molecular weight copolymer inhibitors, such as HPAM, hyperbranched polyglycerols, FA-367, PDADMAC and polyamine have been investigated over the past decades ${ }^{[8-10]}$. The copolymer inhibitors will be wrapped and form a coating film in the surface of clay which can effectively prevent the wellbore instability of

shale. However, high molecular weight copolymer shows a great influence on the rheological property of $\mathrm{WBDFs}^{[8]}$. Besides, the high molecular weight copolymer chain is easy to curl and lose itself function in the environment of high salt, high calcium and high temperature ${ }^{[9]}$.

Works have proved that copolymer with low molecular weight showed excellent salt and temperature resistance ability in WBDFs, and low molecular weight polymers such as polyamine, hyperbranched polymer has greatly aroused the interest of oilfield researcher in drilling operations in the last ten years. Zwitterionic polymers own anionic and cationic group, and have great advantages for maintaining the stability of wellbore ${ }^{[11]}$. Zhao et al. ${ }^{[12]}$ has synthesized a zwitterionic copolymer AM/DMC/AMPS as a low-molecular-weight encapsulator in deep-water drilling fluid which have showed strong clay hydration inhibition performance. However, there are still few reports about low molecular weight zwitterionic copolymer as clay hydration inhibitor so far.

In the present work, SSS and AM were copolymerized with a novel cationic monomer THDAB to synthesize a low molecular weight zwitterionic copolymer clay hydration dispersion inhibitor AM/SSS/THDAB for WBDFs. Where, $\mathrm{AM}$ acts as the backbone, THDAB acts as a functional monomer which ensure the adsorption of AM/SSS/THDAB 
onto the clay surface, SSS acts as a temperature resistant monomer to ensure the copolymer with outstanding salt and temperature resistance performance. The copolymer structure was characterized by FT-IR, GPC, TGA-DSC and SEM. The inhibition performance was evaluated by hot rolling recovery rate experiments and the inhibition mechanism of $\mathrm{AM} / \mathrm{SSS} / \mathrm{THDAB}$ was discussed via particle size analysis and SEM in the text.

\section{Experimental}

\subsection{Materials}

$\mathrm{SSS}$, AM, trolamine, allyl bromide, $\left(\mathrm{NH}_{4}\right)_{2} \mathrm{~S}_{2} \mathrm{O}_{8}, \mathrm{NaHSO}_{3}$, ethanol, ethyl acetate and isopropanol were all of analytical pure and purchased from Kelon Co., Ltd, Chengdu, China. Poly-ECH-DMA with molecular weight $32352 \mathrm{~g} / \mathrm{mol}$ was supplied by Maikeba Mud Co., Ltd, USA. PF-CMJ with molecular weight $2.3 \times 10^{5} \mathrm{~g} / \mathrm{mol}$ and XY-27 with $4362 \mathrm{~g} / \mathrm{mol}$ was received from Engineering Technology Research Institute Co., Ltd., CNPC, Beijing, China. PAM with molecular weight $1.8 \times 10^{5} \mathrm{~g} / \mathrm{mol}$ and FA-367 with molecular weight $1.2 \times 10^{4} \mathrm{~g} / \mathrm{mol}$ were supplied by Sichuan Guangya polymer technology Co., Ltd, Chengdu, China. Na-MMT with cation exchange capacity of $81.3 \mathrm{mmol} / \mathrm{g}$ was obtained from Xia Zijie Bentonite Technology Co., Ltd, Xinjiang, China. The shale samples were obtained from Longmaxi shale gas field, Chongqing, China, and the mineral compositions of shale samples were illustrated in Table 1.

\subsection{Synthesis of polymeric monomer THDAB}

THDAB was prepared based on a method previously reported $^{[13,14]}$, as shown in Figure 1. Briefly, trolamine $(0.20 \mathrm{~mol})$, allyl bromide $(0.20 \mathrm{~mol})$, and ethanol $(150 \mathrm{~mL})$ were placed in a round-bottom flask equipped with a reflux condenser and refluxed for $24 \mathrm{~h}$ with magnetic stirring at

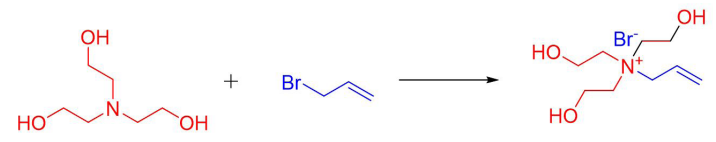

Figure 1. Synthesis route of THDAB.
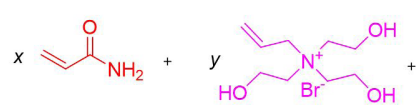

Isopropanol, $65^{\circ} \mathrm{C}$ $\mathrm{K}_{2} \mathrm{~S}_{2} \mathrm{O}_{8}^{-} \mathrm{NaHSO}_{3}$

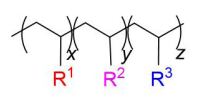

$\mathrm{R}^{1}=\mathrm{H}_{2} \mathrm{~N} \curvearrowright \mathrm{O}$
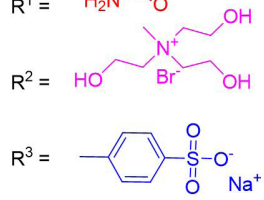

Figure 2. Synthesis route of AM/SSS/THDAB.
$50{ }^{\circ} \mathrm{C}$. After cooling to room temperature, the solution was concentrated under reducing pressure and then redissolved in ethyl acetate and ethanol (ethyl acetate: ethanol $=7: 3$ ). Product was isolated in high yield as a rod-like crystals or white powder after placed in room temperature for $24 \mathrm{~h}$. Yield: $94.3 \%$. ${ }^{1} \mathrm{H} \mathrm{NMR}\left(400 \mathrm{MHz}, \mathrm{D}_{2} \mathrm{O}\right)$ : 5.62-5.75 (m, 1H, CH=C), 4.89 5.07 (m, 2H, C= $\left.\mathrm{CH}_{2}\right)$, $3.75 \sim 3.76(\mathrm{~d}, 6 \mathrm{H}, \mathrm{CH}-\mathrm{O}), 3.60(\mathrm{t}, 2 \mathrm{H},-\mathrm{CH}-\mathrm{C}=\mathrm{C})$, $3.33(\mathrm{t}, 3 \mathrm{H},-\mathrm{OH}), 3.04 \sim 3.06\left(\mathrm{t}, 6 \mathrm{H}, \mathrm{N}-\mathrm{CH}_{2}-\mathrm{C}-\mathrm{OH}\right)$; IR (KBr), $/ \mathrm{cm}^{-1}: 3360,2920,1630,1400,1080,900,520$.

\subsection{Synthesis of AM/SSS/THDAB}

AM/SSS/THDAB was synthesized by redox free radical copolymerization in aqueous solution, the synthesis route of AM/SSS/THDAB is shown in Figure 2. Appropriate $7.2 \mathrm{~g}$ SSS was dissolved in $10 \mathrm{~mL}$ deionized water, the $\mathrm{pH}$ was adjusted to the indicated value at 7.0 by using $30 \mathrm{wt} \%$ $\mathrm{NaOH}$ solutions. Then, $2 \mathrm{~g}$ AM and $4 \mathrm{~g}$ THDAB were added to flask with stirring at constant temperature under nitrogen atmosphere for $20 \mathrm{~min}$. Hereafter, the initiator $\mathrm{K}_{2} \mathrm{~S}_{2} \mathrm{O}_{8}$ and $\mathrm{NaHSO}_{3}$, which the initiator concentration was $1.5 \mathrm{wt} \%$ relative to the total monomer amount were added. The polymerization was carried out at $65{ }^{\circ} \mathrm{C}$ for $0.5 \mathrm{~h}$ while stirring, and then isopropanol was added to the solution, polymerization was preceded at $65^{\circ} \mathrm{C}$ for another $7 \mathrm{~h}$. The target product was obtained by repeatedly washing with ethanol to remove monomers, isopropanol and initiator, AM/SSS/THDAB was further dried under vacuum oven at $65^{\circ} \mathrm{C}$ for $24 \mathrm{~h}$.

\subsection{Characterizations of AM/SSS/THDAB}

FT-IR spectra were recorded via a WQF-520 Fourier transform infrared spectrometer in the wave number range of 4000-500 $\mathrm{cm}^{-1}$. GPC was utilized to measure the molecular weight by using an Alliance e2695 instrument (Waters, USA). The injection volume and operation hours were $50 \mu \mathrm{L}$ and $90 \mathrm{~min}$, respectively. TGA-DSC test was acquired on a simultaneous TGA-DSC (METTLER TOLEDO, Swiss) instrument under nitrogen atmosphere flow $(40 \mathrm{~mL} \mathrm{~min}-1)$ with the heating rate of $10{ }^{\circ} \mathrm{C} \mathrm{min}^{-1}$. SEM analysis of AM/SSS/THDAB solution was obtained with a FEI Quanta 450 instrument, in the magnifying multiple ranges from $500 \times$ to $10000 \times$.

\subsection{Inhibition performance evaluation}

Hot rolling recovery tests were used to study the inhibition ability of AM/SSS/THDAB, and the tests were conducted at $100{ }^{\circ} \mathrm{C}$ for $16 \mathrm{~h}$.

\subsection{Inhibition mechanism study}

\subsubsection{Particle size distribution analysis}

$8 \mathrm{~g} \mathrm{AM} / \mathrm{SSS} / \mathrm{THDAB}$ was added into $400 \mathrm{~mL}$ WBDFs and stirred for $2 \mathrm{~h}$. Then, particle size analysis was measured with a laser diffraction technique (HORIBA, Japan) at room temperature.

Table 1. The mineral compositions of shale sample.

\begin{tabular}{ccccc}
\hline $\begin{array}{c}\text { Mineral } \\
\text { compositions }\end{array}$ & Kaolinite & Chlorite & Illite & $\begin{array}{c}\text { Sodium bentonite } \\
\text { bentonite }\end{array}$ \\
\hline Content $\%$ & 0.0 & 26.3 & 65.1 & 8.6 \\
\hline
\end{tabular}




\subsubsection{SEM analysis}

SEM was investigated with a FEI Quanta 450 instrument, range of the magnifying multiple was from $500 \times$ to $10000 \times$, and the samples were trimmed from the bottom of the API filter cake after the room temperature and room pressure drilling fluids tests.

\section{Results and Discussion}

\subsection{Characterizations of $A M / S S S / T H D A B$}

\subsubsection{FT-IR analysis}

Figure 3 shows the FT-IR spectra of AM, SSS, THDAB and zwitterionic copolymer AM/SSS/THDAB.

For AM/SSS/THDAB, the absorption peak at $3353 \mathrm{~cm}^{-1}$ was due to the-OH stretching of THDAB, the strong absorption peak recorded at $1663 \mathrm{~cm}^{-1}$ was assigned to the stretching vibration of $\mathrm{C}=\mathrm{O}$, the peaks at approximate $1219 \mathrm{~cm}^{-1}$ was assigned to the $-\mathrm{SO}_{3} \mathrm{H}$ stretching vibration, which indicated that SSS was involved in the copolymerization. The peak at $1400 \mathrm{~cm}^{-1}$ and $1025 \mathrm{~cm}^{-1}$ was attributed to the characteristic absorption peak of C-N and C-O-C, respectively ${ }^{[15]}$. FT-IR characterization result demonstrates that AM/SSS/THDAB contains characteristic functional group absorption peaks of each monomer, indicating that AM, SSS and THDAB were successfully copolymerized to the target product.

\subsubsection{Molecular weight measurement}

The average molecular weight of AM/SSS/THDAB was determined by GPC and the result is shown in Figure 4.

Figure 4 shows the molecular weight measurement of AM/SSS/THDAB. AM/SSS/THDAB has a certain width of molecular weight distribution and the $\mathrm{Mp}$ of $\mathrm{AM} / \mathrm{SSS} / \mathrm{THDAB}$ is $43674 \mathrm{~g} / \mathrm{mol}$. With a wide molecular weight distribution, the low molecular weight of AM/SSS/THDAB (800-5000 g/mol) could enter the layer of tetrahedral crystal and compress the diffusion electric double layer of clay ${ }^{[16]}$. In addition, the large molecular weight part could be packed on the clay surface, thereby, to effectively inhibit the hydration dispersion of clay.

\subsubsection{TGA-DSC measurement}

Thermogravimetry (TGA) differential scanning calorimetry (DSC) was utilized to investigate the thermal stability of AM/SSS/THDAB, and the thermal gravimetric curve displayed the four stages for the weight loss.

As shown in Figure 5, the first stage with a loss of 6.92 mass $\%$ in the temperature range of $40-153{ }^{\circ} \mathrm{C}$ was due to the combination of evaporation moisture and AM/SSS/THDAB. The second stage taken place in the temperature range of $153-225^{\circ} \mathrm{C}$ with a loss of 4.73 mass $\%$ was mainly probably due to the decompositions of amide groups and quaternary ammonium groups in the copolymer. The third decomposition temperature occurred in $225-309^{\circ} \mathrm{C}$ with a prodigious loss of 8.33 mass \% was mainly ascribed to the decomposition of AM/SSS/THDAB, which due to the degradation of $\mathrm{C}-\mathrm{C}$ in the side chain ${ }^{[15]}$. The final loss stage in the temperature range of $309-500{ }^{\circ} \mathrm{C}$ with a prodigious loss of 46.86 mass $\%$ indicated that the main structure of $\mathrm{AM} / \mathrm{SSS} / \mathrm{THDAB}$ was destroyed. The result of TGA-DSC demonstrated that AM/SSS/THDAB shows an excellent thermal stability ability.

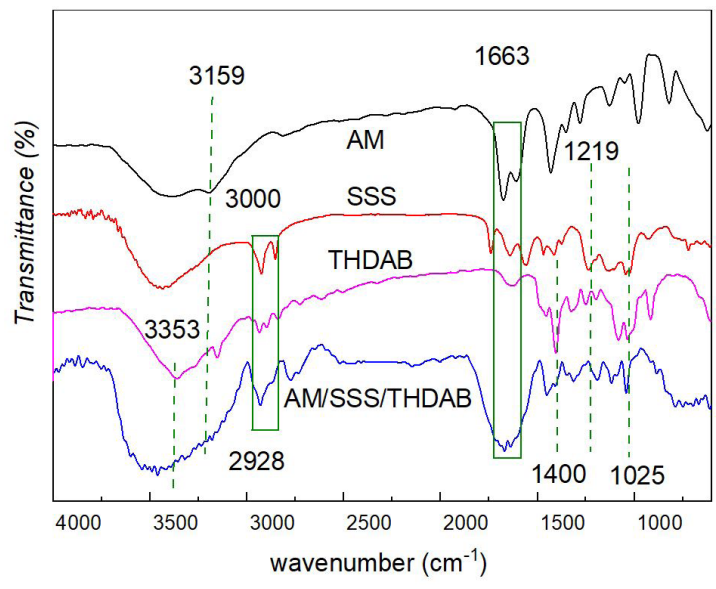

Figure 3. FT-IR spectra of AM, SSS, THDAB and AM/SSS/THDAB.

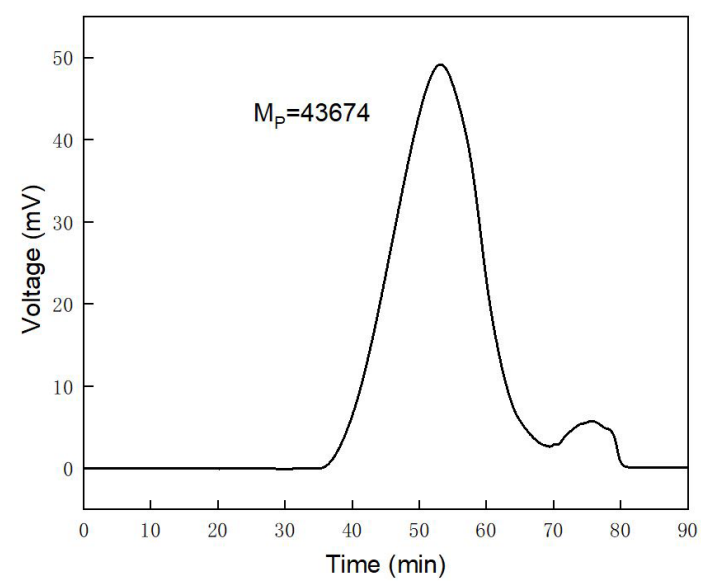

Figure 4. Molecular weight measurement of AM/SSS/THDAB.

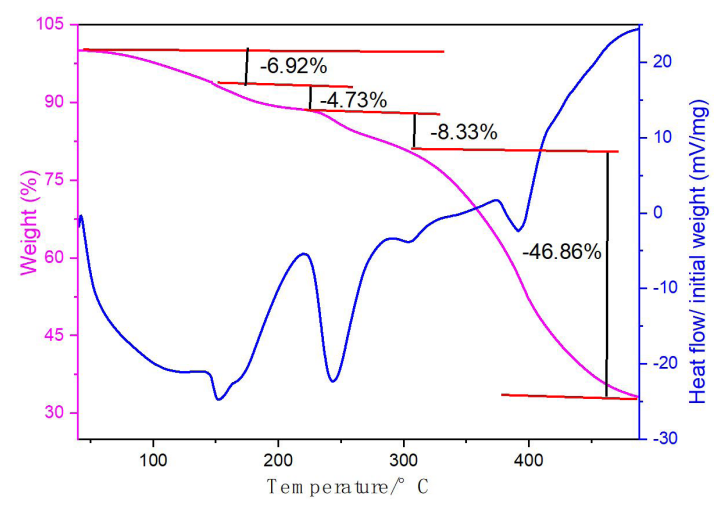

Figure 5. TGA-DSC measurement of AM/SSS/THDAB.

\subsubsection{SEM characterizations}

The SEM characterizations of AM/SSS/THDAB solutions are shown in Figure 6.

From Figure 6, we have observed that the cross-linking structure of AM/SSS/THDAB was not obvious, and the polymer was mainly stretched on the main chain. Due to 

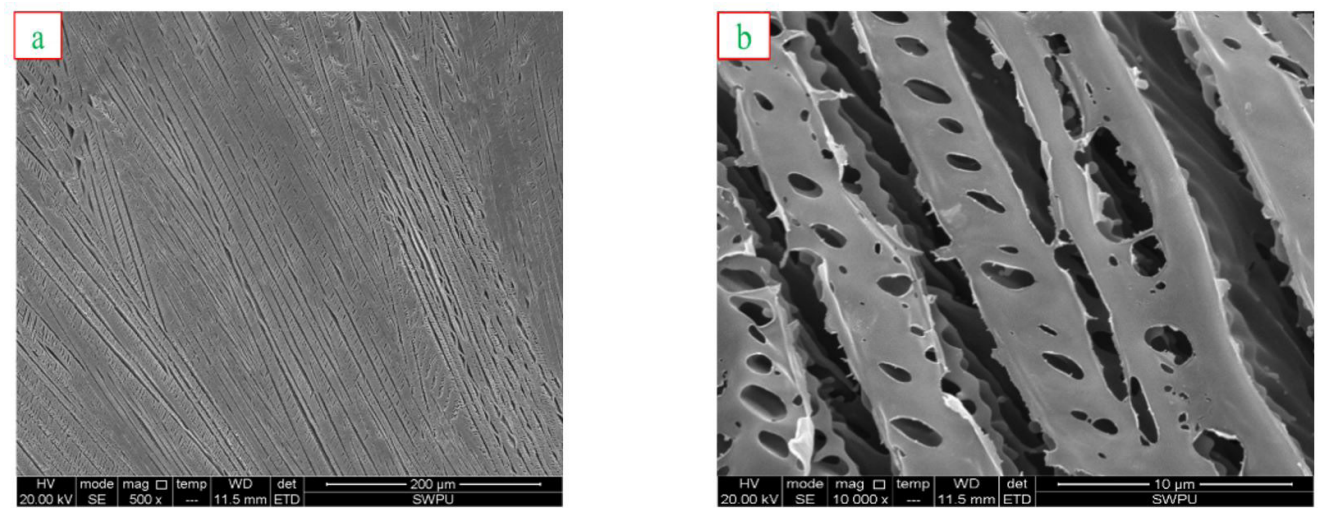

Figure 6. SEM images of AM/SSS/THDAB: 1000×, scale bar $200 \mu \mathrm{m}$ (a) $10000 \times$, scale bar $50 \mu \mathrm{m}$ (b).

Table 2. Inhibition performance evaluation of AM/SSS/THDAB aqueous solution.

\begin{tabular}{|c|c|c|c|c|c|}
\hline Concentration (wt \%) & $\mathrm{AV} / \mathbf{m P a} \cdot \mathbf{s}$ & $\mathrm{PV} / \mathrm{mPa} \cdot \mathbf{s}$ & $\mathbf{Y P} / \mathbf{P a}$ & $\Phi 6 / \Phi 3$ & $\begin{array}{c}\text { Rolling recovery } \\
\text { rate } / \%\end{array}$ \\
\hline 0.5 & 5.0 & 5.0 & 0 & $1 / 1$ & 34.6 \\
\hline 1.0 & 7.5 & 5.0 & 2.5 & $1 / 1$ & 53.7 \\
\hline 1.5 & 8.0 & 5.0 & 3 & $1 / 1$ & 79.3 \\
\hline 2.0 & 9.5 & 7.0 & 2.5 & $1 / 1$ & 83.6 \\
\hline 2.5 & 10.0 & 8.0 & 2 & $2 / 1$ & 83.9 \\
\hline 3.0 & 12.5 & 10.0 & 2.5 & $2 / 1$ & 84.1 \\
\hline
\end{tabular}

Rolling condition: $100^{\circ} \mathrm{C} \times 16 \mathrm{~h}$

the sulfonamide structures of SSS and amide groups of $\mathrm{AM}$ in $\mathrm{AM} / \mathrm{SSS} / \mathrm{THDAB}$, cross-linking interaction and intramolecular interaction were occurred, and the speculation has also been confirmed by SEM characterization. However, the rope-like molecular structure still can guarantee the covering of $\mathrm{AM} / \mathrm{SSS} / \mathrm{THDAB}$ on the clay surface.

\subsection{Inhibition performance evaluation}

The hot-rolling recovery tests were carried out to study the inhibition property of AM/SSS/THDAB and several clay hydration inhibitors which are commonly used in oilfield.

Table 2 shows the effect of AM/SSS/THDAB on its solution viscosity and clay rolling recovery rate. From the results, we can see that with the increasing of AM/SSS/ THDAB concentration, the viscosity of polymer aqueous solutions and shale hot rolling recovery rate have increased. When the polymer concentration was $2 \mathrm{wt} \%$, the rolling recovery has reached $83.6 \%$, and with the increasing of polymer concentration, the change of shale rolling recovery rate was not obvious yet.

The clay inhibition property of AM/SSS/THDAB and several clay hydration inhibitors commonly used in oilfield were compared in this work, as shown in Table 3.

As shown in Table 3, zwitterionic inhibitor XY-27 shows the limited inhibition performance leading to the rolling recovery rate of clay in its solutions was only $56.8 \%$. The coating agent FA-367 demonstrated a nice clay hydration dispersion inhibitive performance and the clay rolling recovery rate has reach to $82.6 \%$. As a film-forming plugging agent, Poly-ECH-DMA and PF-CMJ can adsorb on the clay surface because there are a large amount of absorbable groups on them ${ }^{[17-19]}$, and the excellent clay hydration inhibition ability with the rolling
Table 3. Inhibition performance study of inhibitors.

\begin{tabular}{cc}
\hline Inhibitor & Rolling recovery rate/\% \\
\hline $2.0 \mathrm{wt} \% \mathrm{AM} / \mathrm{SSS} / \mathrm{THDAB}$ & 83.6 \\
$0.5 \mathrm{wt} \%$ XY- 27 & 56.8 \\
$0.5 \mathrm{wt} \% \mathrm{FA}-367$ & 82.6 \\
$2.0 \mathrm{wt} \%$ Poly-ECH-DMA & 79.2 \\
$0.5 \mathrm{wt} \%$ PAM & 62.3 \\
$2.0 \mathrm{wt} \% \mathrm{PF}-\mathrm{CMJ}$ & 72.6 \\
\hline
\end{tabular}

recovery rate of clay was $79.2 \%$ and $72.6 \%$, respectively. From the above results we can conclude that for all cases, copolymer inhibitors evaluated in this work all showed superior clay hydration dispersion inhibition performance.

\subsection{Inhibition mechanism analysis}

\subsubsection{Particle distribution tests}

It is well known that the negative charge surface of clay is trendy to be neutralized by the positive charge of cations, and flocculation will be happened when positive polymer was added to the WBDFs ${ }^{[20-22]}$. The inhibition mechanism was evaluated by particle distribution tests, and the results are shown in Figure 7.

As shown in Figure 7, for the case in distilled water, Na-MMT illustrated tiny average particle size of $33.06 \mu \mathrm{m}$, and the average particle size of Na-MMT has been increased to $425.37 \mu \mathrm{m}$ in $2.0 \mathrm{wt} \% \mathrm{AM} / \mathrm{SSS} / \mathrm{THDAB}$ solutions. For the reason that zwitterionic $\mathrm{AM} / \mathrm{SSS} / \mathrm{THDAB}$ can be coated on the surface of clay to inhibit the hydration dispersion of clay and in that way to make the particle size obviously increased. Particle distribution tests have shown that AM/SSS/THDAB can form an effective coating on the clay surface. 


\subsubsection{SEM observations}

SEM is a convenient technology to observe the morphological changes of material surface. The surface morphologies of Na-MMT without AM/SSS/THDAB and with AM/SSS/THDAB were analyzed by using SEM and the images are showed in Figure 8.

During the preparation process of samples, there was a light pressure $(0.69 \mathrm{MPa})$ on the surface of the muds cake. For the Na-MMT without AM/SSS/THDAB, there were large holes in the muds cake, which indicated the poor bonding force between $\mathrm{Na}-\mathrm{MMT}$ particles ${ }^{[23,24]}$. In contrast, after treated with $2 \mathrm{wt} \% \mathrm{AM} / \mathrm{SSS} / \mathrm{THDAB}$, there were thin polymer films on the muds cake surface, which indicating

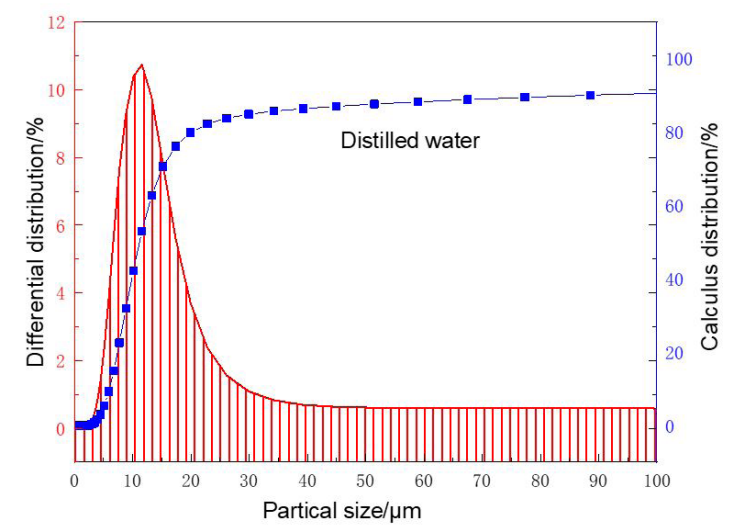

Figure 7. Particle distribution tests.

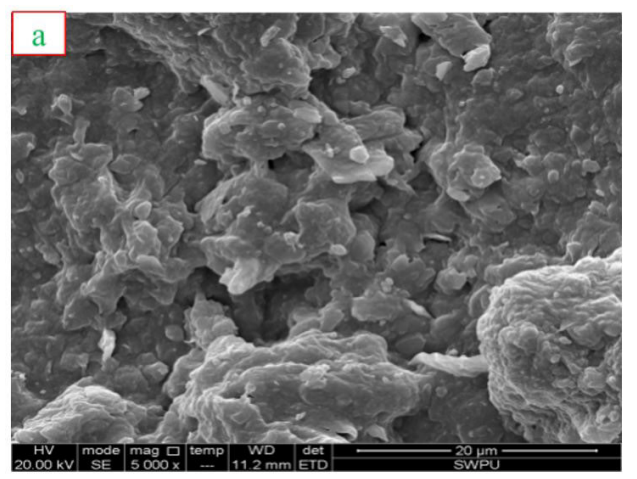

that AM/SSS/THDAB can inhibit the clay dispersion by wrapping in the clay surface.

Through the inhibition mechanism analysis of AM/SSS/THDAB by the above two methods, and reference to swelling inhibition mechanism analysis reported by other work, we have proposed the clay hydration dispersion inhibition mechanism of AM/SSS/THDAB, which is shown in Figure 9. In the hot-rolling recovery tests, we found that AM/SSS/THDAB showed excellent hydration inhibition property, a possible explanation to the result might be that the larger molecular weight part of AM/SSS/THDAB can be wrapped on clay surface because there are hydroxyl and quaternary ammonium functional groups in the side chain of copolymer. What's more, dispersion was not easy
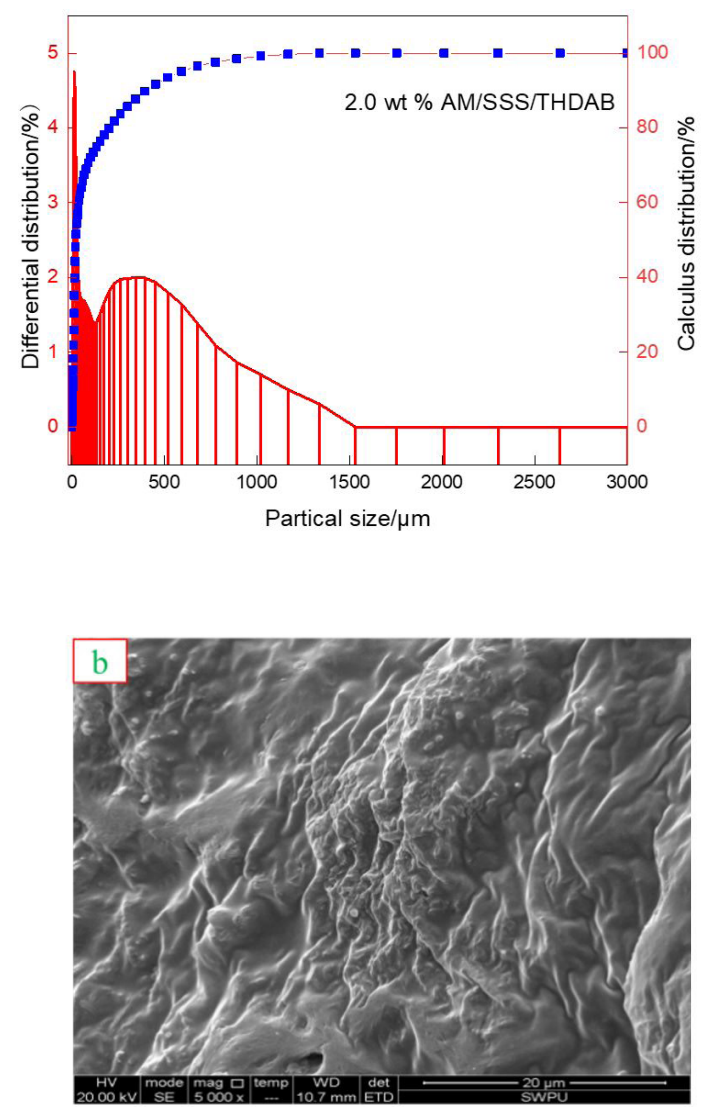

Figure 8. SEM observations of Na-MMT composites ( $\times 5000)$ : (a) basic muds cake; (b) treated with 2 wt $\%$ AM/SSS/THDAB.
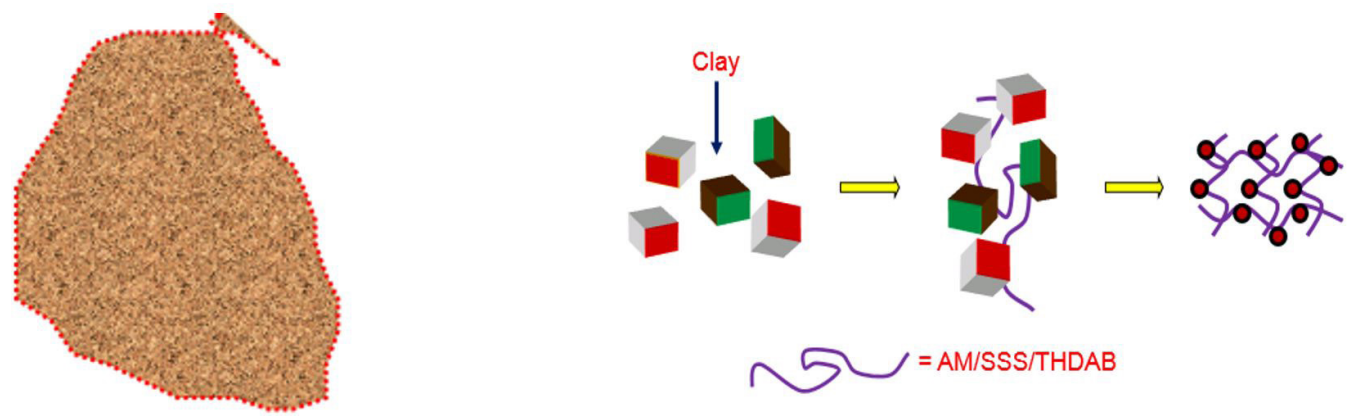

Figure 9. Inhibition mechanism analysis of AM/SSS/THDAB. 
to occur while clay particles fixed on the long chain of AM/SSS/THDAB.

\section{Conclusions}

In conclusion, a zwitterionic copolymer clay hydration dispersion inhibitor AM/SSS/THDAB for WBDFs was successfully prepared by THDAB, SSS and AM. The copolymer was characterized by FT-IR, GPC, TGA-DSC and SEM, results showed the molecular weight of AM/SSS/THDAB was $43674 \mathrm{~g} / \mathrm{mol}$ and showed an excellent temperature resistance ability. Its inhibition performance and mechanism were systematically investigated by a range of methods, evaluation experiments indicated that AM/SSS/THDAB possessed superior inhibition properties compared with several inhibitors. Through the analysis of inhibition mechanism, three key points such as the multiple driven forces, wide molecular weight distribution and the long chain of copolymer could ensure the perfect inhibition performance of AM/SSS/THDAB. All these features indicate that $\mathrm{AM} / \mathrm{SSS} / \mathrm{THDAB}$ could be a potential clay hydration dispersion inhibitor for wellbore stability in drilling engineering.

\section{Acknowledgements}

The authors would like to thank the Open Fund (KFKT2019-13) of the Key Laboratory of Auxiliary Chemistry and Technology for Chemical Industry, Ministry of Education Shaanxi University of Science and Technology for financial support.

\section{References}

1. Fagundes, K. R. S., Luz, R. C. S., Fagundes, F. P., \& Balaban, R. C. (2018). Effect of carboxymethylcellulose on colloidal properties of calcite suspensions in drilling fluids. Polímeros: Ciência e Tecnologia, 28(4), 373-379. http://dx.doi. org/10.1590/0104-1428.11817.

2. Chen, S. Y., Shi, Y. P., Yang, X. Y., Xie, K. Z., \& Cai, J. H. (2019). Design and evaluation of a surfactant-mixed metal hydroxide-based drilling fluid for maintaining wellbore stability in coal measure strata. Energies, 12(10), 1862-1881. http:// dx.doi.org/10.3390/en12101862.

3. Wilson, M. J., \& Wilson, L. (2014). Clay mineralogy and shale instability: an alternative conceptual analysis. Clay Minerals, 49(2), 127-145. http://dx.doi.org/10.1180/claymin.2014.049.2.01.

4. Anderson, R. L., Ratcliffe, I., Greenwell, H. C., Williams, P. A., Cliffe, S., \& Coveney, P. V. (2010). Clay swelling: a challenge in the oilfield. Earth-Science Reviews, 98(3-4), 201-216. http://dx.doi.org/10.1016/j.earscirev.2009.11.003.

5. Gholami, R., Elochukwu, H., Fakhari, N., \& Sarmadivaleh, M. (2018). A review on borehole instability in active shale formations: Interactions, mechanisms and inhibitors. EarthScience Reviews, 177, 2-13. http://dx.doi.org/10.1016/j. earscirev.2017.11.002.

6. Du, W. C., Wang, X. Y., Chen, G., Zhang, J., \& Slaný, M. (2020). Synthesis, property and mechanism analysis of a novel polyhydroxy organic amine shale hydration inhibitor. Minerals, 10(2), 128-142. http://dx.doi.org/10.3390/min10020128.

7. Rana, A., Arfaj, M. K., \& Saleh, T. A. (2019). Advanced developments in shale inhibitors for oil production with low environmental footprints-A review. Fuel, 247, 237-249. http:// dx.doi.org/10.1016/j.fuel.2019.03.006.
8. Ahmed, H. M., Kamal, M. S., \& Al-Harthi, M. (2019). Polymeric and low molecular weight shale inhibitors: a review. Fuel, 251, 187-217. http://dx.doi.org/10.1016/j.fuel.2019.04.038.

9. Ghaderi, S., Ramazani S.A, A., \& Haddadi, S. A. (2019). Applications of highly salt and highly temperature resistance terpolymer of acrylamide/styrene/maleic anhydride monomers as a rheological modifier: rheological and corrosion protection properties studies. Journal of Molecular Liquids, 294, 111635111646. http://dx.doi.org/10.1016/j.molliq.2019.111635.

10. Abdollahi, M., Pourmahdi, M., \& Nasiri,A. (2018). Synthesis and characterization of lignosulfonate/acrylamide graft copolymers and their application in environmentally friendly water-based drilling fluid. Journal of Petroleum Science Engineering, 171, 484-494. http://dx.doi.org/10.1016/j.petrol.2018.07.065.

11. Jia, H., Huang, P., Wang, Q. X., Han, Y. G., Wang, S. Y., Zhang, F., Pan, W., \& Lv, K. H. (2019). Investigation of inhibition mechanism of three deep eutectic solvents as potential shale inhibitors in water-based drilling fluids. Fuel, 244, 403-411. http://dx.doi.org/10.1016/j.fuel.2019.02.018.

12. Zhao, X., Qiu, Z. S., Zhang, Y. J., Zhong, H. Y., Huang, W. A., \& Tang, Z. C. (2017). Zwitterionic polymer P (AM-DMCAMPS) as a low-molecular-weight encapsulator in deepwater drilling fluid. Apply. Science, 7(6), 594-810. http://dx.doi. org/10.3390/app7060594.

13. Pu, X. L., Du, W. C., Sun, J. S., Luo, X., \& Zhang, H. D. (2016). Synthesis and application of a novel polyhydroxy amine clay anti-swelling agent. Petrochemical Technology, 45, 595-600.

14. Silva, F. A., Siopa, F., Figueiredo, B. F. H. T., Gonçalves, A. M. M., Pereira, J. L., Gonçalves, F., Coutinho, J. A. P., Afonso, C. A. M., \& Ventura, S. P. M. (2014). Sustainable design for environment-friendly monoand dicationic cholinium-based ionic liquids. Ecotoxicology and Environmental Safety, 108, 302-310. http://dx.doi.org/10.1016/j.ecoenv.2014.07.003. PMid:25108510.

15. Paz, R. A., Leite, A. M. D., Araújo, E. M., Medeiros, V. N., Melo, T. J. A., \& Pessan, L. A. (2016). Mechanical and thermomechanical properties of polyamide 6/Brazilian organoclay nanocomposites. Polímeros: Ciência e Tecnologia, 26(1), 52-60. http://dx.doi.org/10.1590/0104-1428.1748.

16. Jain, R., \& Mahto, V. (2015). Evaluation of polyacrylamide/ claycomposite as a potential drilling fluid additive in inhibitive water based drilling fluid system. Journal of Petroleum Science Engineering, 133, 612-621. http://dx.doi.org/10.1016/j. petrol.2015.07.009.

17. Costa, L. P., Jr., Silva, D. B. R., Aguiar, M. F., Melo, C. P., \& Alves, K. G. B. (2019). Preparation and characterization of polypyrrole/organophilicmontmorillonite nanofibers obtained by electrospinning. Journal of Molecular Liquids, 275, 452462. http://dx.doi.org/10.1016/j.molliq.2018.11.084.

18. Salles, F., Douillard, J.-M., Bildstein, O., Gaudin, C., Prelot, B., Zajac, J., \& Van Damme, H. (2013). Driving force for the hydration of the swelling clays: case of montmorillonites saturated with alkaline-earth cations. Journal of Colloid and Interface Science, 395, 269-276. http://dx.doi.org/10.1016/j. jcis.2012.12.050. PMid:23352873.

19. Boek, E. S., Coveney, P. V., \& Skipper, N. T. (1995). Monte carlo molecular modeling studies of hydrated Li-, Na-, and $\mathrm{K}$-smectites: understanding the role of potassium as a clay swelling inhibitor. Journal of the American Chemical Society, 117(50), 12608-12617. http://dx.doi.org/10.1021/ja00155a025.

20. Caglar, B., Çırak, Ç., Tabak, A., Afsin, B., \& Eren, E. (2013). Covalent grafting of pyridine-2-methanol into kaolinite layers. Journal of Molecular Liquids, 1032, 12-22. http://dx.doi. org/10.1016/j.molstruc.2012.08.004.

21. Du, W. C., Pu, X. L., Sun, J. S., Luo, X., Zhang, Y. N., \& Li, L. (2018). Synthesis and evaluation of a novel monomeric amine 
as sodium montmorillonite swelling inhibitor. Adsorption Science and Technology, 36(1-2), 655-668. http://dx.doi. org/10.1177/0263617417713851.

22. Caglar, B., Topcu, C., Coldur, F., Sarp, G., Caglar, S., Tabak, A., \& Sahin, E. (2016). Structural, thermal, morphological and surface charge properties of dodecyltrimethylammonium-smectite composites. Journal of Molecular Liquids, 1105, 70-79. http://dx.doi. org/10.1016/j.molstruc.2015.10.017.

23. Pérez, A., Montes, M., Molina, R., \& Moreno, S. (2014). Modified clays as catalysts for the catalytic oxidation of ethanol.
Applied Clay Science, 95, 18-24. http://dx.doi.org/10.1016/j. clay.2014.02.029.

24. Gang, C., Gao, L., Sun, Y., Gu, X., Hu, W., Du, W., Zhang, J., \& Qu, C. (2019). A green shale inhibitor developed from lignin sulfonate and a mechanism study. Journal of Biobased Materials and Bioenergy, 13(6), 778-783. http://dx.doi. org/10.1166/jbmb.2019.1908.

Received: Aug. 27, 2019

Revised: Oct. 25, 2019

Accepted: Feb. 03, 2020 